\title{
The Association Between Fasting C-peptide and Gastrointestinal Symptoms of Gastroparesis in Type 2 Diabetic Patients
}

\author{
Yun Huang, Honghong Zhang, Minxia Zhang, Wenya Li, Jinhua Wang, and Ji Hu* \\ Department of Endocrinology, The Second Affiliated Hospital of Soochow University, Suzhou, Jiangsu, China
}

\section{Background/Aims}

The relationship between C-peptide levels and gastrointestinal (GI) symptoms in type 2 diabetic patients is not clear. The purpose of this study is to examine the association between fasting C-peptide and Gl symptoms of gastroparesis in type 2 diabetic patients.

\section{Methods}

We recruited 333 type 2 diabetic patients into the present study. All patients filled out questionnaires of gastroparesis cardinal symptom index (GCSI) to evaluate Gl symptoms. Hospital anxiety and depression scale were adopted to define anxiety and depression. Patients with GCSI scores $\geq 1.9$ were regarded as having symptoms of gastroparesis.

\section{Results}

In our study, $71(21.3 \%)$ type 2 diabetic patients had GCSI scores $\geq 1.9$. In comparison to patients with scores $<1.9$, those with scores $\geq 1.9$ had significantly lower fasting c-peptide levels $(1.49 \mathrm{ng} / \mathrm{mL}$ vs $1.94 \mathrm{ng} / \mathrm{mL}, P<0.001)$, higher prevalence of depression $(40.9 \%$ vs $18.3 \%, P<0.001)$ and anxiety $(28.2 \%$ vs $13.0 \%, P=0.002)$. Multivariate logistic regression revealed that fasting C-peptide was still significantly associated with symptoms of gastroparesis (odds ratio, $0.67 ; 95 \%$ confidence intervals, $0.48-0.94 ; P$ $=0.021$ ), even after adjustments for age, sex, body mass index, HbA1c, current smoking and drinking status, anxiety, and depression. Furthermore, linear regressions showed that fasting C-peptide was independently and negatively related to GCSI scores (standardized regression coefficient, $-0.29 ; P<0.001)$ in patients with at least one $\mathrm{Gl}$ symptom.

\section{Conclusion}

GI symptoms of diabetic gastroparesis affect approximately $20 \%$ of type 2 diabetes patients and are associated with lower fasting C-peptide levels independent of depression and anxiety status.

\section{(J Neurogastroenterol Motil 2017;23:254-261)}

\section{Key Words}

Anxiety disorders; C-peptide; Depressive disorder; Diabetes mellitus, Type 2; Gastroparesis

\section{Received: June 8, 2016 Revised: October 5, 2016 Accepted: October 9, 2016}

(5) This is an Open Access article distributed under the terms of the Creative Commons Attribution Non-Commercial License (http://creativecommons. org/licenses/by-nc/4.0) which permits unrestricted non-commercial use, distribution, and reproduction in any medium, provided the original work is properly cited.

*Correspondence: Ji Hu, MD, PhD

Department of Endocrinology, The Second Affiliated Hospital of Soochow University, 1055 Sanxiang Road, Suzhou, Jiangsu, China Tel: +86-512-67784169, Fax: +86-512-67784166, E-mail: huji@suda.edu.cn 


\section{Introduction}

Diabetic gastroparesis is a well-established complication of diabetes. It is characterized by a constellation of upper gastrointestinal (GI) symptoms including nausea, vomiting, early satiety or postprandial fullness, bloating, and epigastric pain, which results from delayed gastric emptying (GE) in the absence of mechanical obstruction. ${ }^{1}$ The cumulative 10 -year incidence of gastroparesis has been estimated at $1 \%$ in type 2 diabetes among community patients with diabetes; ${ }^{2}$ however, the prevalence of GI symptoms in diabetic patients are much higher. ${ }^{3-5}$ Although the prevalence of GI symptoms varies between different studies due to different study populations and different scales of GI symptoms, most population-based studies found that GI symptoms were increased in diabetic patients as compared with nondiabetic controls. ${ }^{5-7}$ GI symptoms of gastroparesis can adversely affect pharmacokinetics of oral glucose lowering drugs and the absorption of food which can lead to postprandial hypoglycemia in patients who are receiving insulin treatment. Moreover, emerging epidemiological studies provided evidence that GI symptoms can not only impair quality of life (QOL), but is associated with higher mortality and morbidity. ${ }^{8}$

Despite the great harm of GI symptoms, the pathogenesis of GI symptoms in diabetic patients is not fully understood. Autonomic neuropathy is a well-recognized cause of GI symptoms in diabetic patients. ${ }^{9,10}$ Recent studies indicated that c-peptide replacement therapy could ameliorate symptoms of autonomic neuropathy in type 1 diabetic patients. ${ }^{11,12}$ The results made us speculate whether there is a close association between c-peptide levels and GI symptoms in type 2 diabetic patients.

Chronic hyperglycemia is assumed to be associated with GI symptoms. ${ }^{13-19}$ However, results were inconsistent. Several studies claimed that poor glycemic control also linked to higher prevalence of GI symptoms. ${ }^{13-16}$ Nevertheless, in a longitudinal population study, investigators failed to find an association between glycemic control and GI symptoms. ${ }^{20}$ Psychiatric disorders are also believed to affect GI symptoms. Diabetic patients with depression and anxiety had a 2-fold higher prevalence of GI symptoms, which implies that psychiatric disorders contribute greatly to the high prevalence of GI symptoms in diabetic patients. ${ }^{18}$

Therefore, the purpose of the present study is to assess the prevalence of GI symptoms of gastroparesis in type 2 diabetic patients and the association with fasting c-peptide levels, and furthermore, to determine whether the association is independent of psychiatric disorders.

\section{Materials and Methods}

\section{Population}

During December 2012 to July 2013, we consecutively included 333 diabetic patients who were referred to the out-patient clinic or admitted to hospitals of the second affiliated hospital of Soochow University. Patients with inflammatory diseases, GI diseases and histories of abdominal surgeries were excluded. The study protocol was approved by the Institutional Review Board of the second affiliated hospital of Soochow University, and written informed consent was obtained before the recruitment.

\section{Clinical and Biochemical Measurements}

Detailed information about medical histories and lifestyles including smoking and drinking habits were collected by trained physicians. Questionnaire of Gastroparesis Cardinal Symptom Index (GCSI) was used to evaluate GI symptoms and the Hospital Anxiety and Depression Scale (HADS) to determine symptoms of anxiety and depression. The GCSI consists of 3 sub-scales 9 items, which are nausea/vomiting (3 items), post-prandial fullness/early satiety (4 items), and bloating ( 2 items). All symptoms are rated from none ( 0 ) to very severe (5) and GCSI score is calculated as the mean of the 3 sub-scales. Patients with GCSI $\geq 1.9$ were regarded as having symptoms of gastroparesis. ${ }^{21}$ The HADS contains 14 items, 7 items on depression and 7 items on anxiety. A score of 8 or above is considered abnormal. ${ }^{22}$

Each participant received anthropometric measurements which included body weight, body height, and waist circumference. Body weight and height were measured in light clothes and bare feet to the nearest $0.1 \mathrm{~kg}$ and $0.5 \mathrm{~cm}$, respectively. Body mass index (BMI) was calculated according to the formula: BMI $\left(\mathrm{kg} / \mathrm{m}^{2}\right)=$ weight $(\mathrm{kg}) /$ height $(\mathrm{m})^{2}$. Waist circumference (WC) was measured at the umbilical level in the late exhalation phase while the patient was standing. Blood pressure was measured on the non-dominant arm in a seated position after a 10-minute rest, using a mercury sphygmomanometer (Yuyue XJ11D, Jiangsu Yuyue Medical Instrument Co. Ltd., Guangzhou, China).

Before blood samples were collected, all participants fasted for at least 8 hours. Serum glucose, total cholesterol, high density lipoprotein (HDL)-cholesterol, low density lipoprotein (LDL)cholesterol, triglycerides (TG), and creatinine were measured using an automated biochemical instrument (Cobas 8000, Roche, Basel, Switzerland). Glycated hemoglobin A1c (HbAlc) was measured 
by high-performance liquid chromatography (HPLC, Bio_Rad Laboratories, Hercules, CA, USA). Electrochemiluminescence method (Roche Diagnostics GmbH, Mannheim, Germany) was used to assess the levels of $\mathrm{C}$-peptides.

\section{Statistical Methods}

Based on the results from our preliminary study, we used the software PASS 11.0 to calculate the sample size. With the significant level set at 0.05 and power at 0.9 , the calculated sample size turned out to be 304. All statistical analyses were performed using SAS version 9.3 (SAS Institute, Cary, NC, USA). Data were presented as means \pm standard deviation (SD) or medians (interquartile ranges). Fasting serum TG, C-peptide, creatinine, duration of diabetes, and GCSI scores were logarithmically transformed before analyses due to a non-normal distribution. Comparisons between different groups were tested using $t$ test or $\chi^{2}$-test. Spearman correlation was adopted to assess the relationships between clinical, biochemical variables and GCSI scores. In linear regression models, GCSI scores were logarithmically transformed and treated as the dependent variable; age, sex, BMI, HbA1c, duration of diabetes, systolic blood pressure, diastolic blood pressure, TG, TC, HDLc, LDL-c, depression, anxiety, and smoking and drinking status, as well as fasting C-peptide were included in the model as the independent variables. Logistic regression was also used to evaluate the association between c-peptide and symptoms of gastroparesis. Twosided $P$-values $<0.05$ were considered statistically significant.

\section{Results}

\section{Baseline Characteristics of the Study Population}

Baseline characteristics of the study population are displayed in Table 1. WC, creatinine, proportions of current smokers and drinkers were significantly higher in men than in women (all $P<0.05$ ), while systolic blood pressure and proportion of depression were higher in women as compared with men. In contrast, age, BMI, diastolic blood pressure, FBG, HbA1c, fasting C-peptide, lipids levels, duration of diabetes, and proportion of anxiety did not differ significantly between men and women (all $P>0.05$ ).

\section{Prevalence of Gastrointestinal Symptoms of Gastroparesis}

In the study population, $62.2 \%$ of the diabetic patients had at least one GI symptom. Among the GI symptoms, the item "stom-

Table 1. Clinical and Biochemical Characteristics of the Study Population

\begin{tabular}{|c|c|c|c|}
\hline Variables & $\begin{array}{c}\text { Men } \\
(\mathrm{n}=206)\end{array}$ & $\begin{array}{c}\text { Women } \\
(\mathrm{n}=127)\end{array}$ & $P$-value \\
\hline Age (yr) & $61.8 \pm 12.4$ & $61.9 \pm 12.4$ & 0.970 \\
\hline $\operatorname{BMI}\left(\mathrm{kg} / \mathrm{m}^{2}\right)$ & $24.2 \pm 2.9$ & $24.4 \pm 4.7$ & 0.710 \\
\hline $\mathrm{WC}(\mathrm{cm})$ & $89 \pm 10$ & $85 \pm 10$ & 0.002 \\
\hline $\mathrm{SBP}(\mathrm{mmHg})$ & $132 \pm 14$ & $136 \pm 18$ & 0.028 \\
\hline $\mathrm{DBP}(\mathrm{mmHg})$ & $78 \pm 10$ & $80 \pm 10$ & 0.190 \\
\hline $\mathrm{FPG}(\mathrm{mmol} / \mathrm{L})$ & $8.9 \pm 3.6$ & $9.0 \pm 3.3$ & 0.680 \\
\hline $\mathrm{HbA1c}(\%)$ & $8.4 \pm 2.3$ & $8.5 \pm 2.0$ & 0.490 \\
\hline C-peptide (ng/mL) & $1.94(1.20-2.87)$ & $1.80(1.02-2.30)$ & 0.210 \\
\hline Duration of diabetes (yr) & $10(6-13)$ & $10(7-13)$ & 0.430 \\
\hline $\mathrm{TG}(\mathrm{mmol} / \mathrm{L})$ & $1.54(1.10-2.16)$ & $1.58(1.11-2.14)$ & 0.460 \\
\hline $\mathrm{TC}(\mathrm{mmol} / \mathrm{L})$ & $4.70 \pm 1.28$ & $4.73 \pm 1.13$ & 0.830 \\
\hline HDL-c (mmol/L) & $1.29 \pm 0.47$ & $1.27 \pm 0.31$ & 0.610 \\
\hline LDL-c (mmol/L) & $2.62 \pm 0.89$ & $2.66 \pm 0.72$ & 0.670 \\
\hline Creatinine $(\mathrm{mmol} / \mathrm{L})$ & $76(67-87)$ & $65(49-78)$ & $<0.001$ \\
\hline Current smoker (n $[\%])$ & $118(57.3)$ & $6(4.7)$ & $<0.001$ \\
\hline Current drinker (n $[\%]$ ) & $116(56.3)$ & $4(3.2)$ & $<0.001$ \\
\hline Anxiety (n [\%]) & $27(13.1)$ & $27(21.3)$ & 0.050 \\
\hline Depression (n [\%]) & $38(18.5)$ & $39(30.7)$ & 0.010 \\
\hline
\end{tabular}

BMI, body mass index; WC, waist circumference; SBP, systolic blood pressure; DBP, diastolic blood pressure; FPG, fasting plasma glucose; HbA1c, glycated hemoglobin A1c; TG, triglycerides; TC, total cholesterol; HDL-c, high density lipoprotein cholesterol; LDL-c, low density lipoprotein cholesterol.

Data are means $\pm \mathrm{SD}$ or medians (interquartile ranges) or numbers (percentage) of patients. 
Table 2. Prevalence of Gastrointestinal Symptoms of Gastroparesis in Patients with Type 2 Diabetes

\begin{tabular}{lccc}
\hline \multicolumn{1}{c}{ Items } & Men (n [\%]) & Women (n [\%]) & Total (n [\%]) \\
\hline Nausea & $29(14.1)$ & $28(22.1)$ & $57(17.1)$ \\
Retching & $20(9.7)$ & $20(15.8)$ & $40(12.0)$ \\
Vomiting & $16(7.8)$ & $11(8.7)$ & $27(8.11)$ \\
Stomach fullness & $57(27.7)$ & $30(23.6)$ & $87(26.1)$ \\
Inability to finish a normal-sized meal & $45(21.8)$ & $39(30.7)$ & $84(25.2)$ \\
Feeling excessively full after meals & $45(21.8)$ & $34(26.8)$ & $79(23.7)$ \\
Loss of appetite & $42(20.4)$ & $27(21.3)$ & $78(23.4)$ \\
Bloating & $49(23.8)$ & $53(41.7)$ & $76(22.8)$ \\
Stomach or belly visibly larger after meals & $72(35.0)$ & $125(37.5)$ & \\
\hline
\end{tabular}

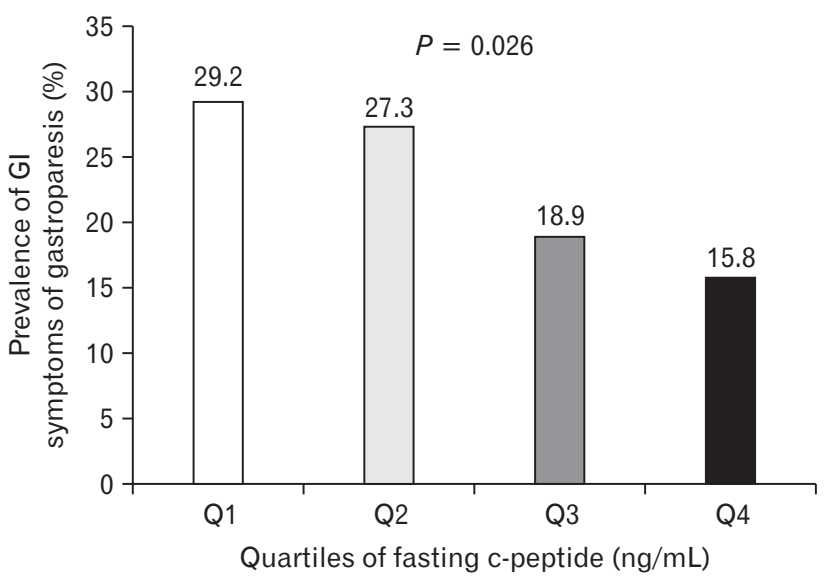

Figure. Prevalence of gastrointestinal (GI) symptoms of gastroparesis in different fasting C-peptide levels. Quartiles of fasting C-peptide levels: Q1, < 1.14ng/mL; Q2, 1.14-1.84 ng/mL; Q3, 1.84-2.65 ng/ $\mathrm{mL}$; and $\mathrm{Q} 4,>2.65 \mathrm{ng} / \mathrm{mL}$.

ach or belly visibly larger after meals" is the most frequent, with the prevalence of $37.5 \%$ (125/333). Vomiting is the least frequent with the prevalence of $8.1 \%$ (27/333). Prevalence of GI symptoms is listed in Table 2. A patient with a GCSI score $\geq 1.9$ was regarded as having symptoms of gastroparesis. In the present study, $21.3 \%$ (71/333) of patients had symptoms of gastroparesis. We further analyzed the prevalence of symptoms of gastroparesis in different C-peptide levels. From the lowest to the highest quartiles of fasting c-peptide levels, the prevalence of symptoms of gastroparesis was $29.2 \%, 27.3 \%, 18.9 \%$, and $15.8 \%$, respectively, which was inversely associated with fasting $\mathrm{C}$-peptide levels $(P=0.026$; Figure $)$.

\section{Relationships Between Gastrointestinal Symptoms of Gastroparesis and Clinical Variables}

We further compared the clinical and biochemical characteristics in patients with or without symptoms of gastroparesis. Patients with GCSI scores $\geq 1.9$ had remarkably lower levels of fasting C-peptide (median 1.49 [interquartile ranges $0.93-2.31$ ] vs 1.94 [1.24-2.85] ng/mL, $P=0.005$; Table 3), higher prevalence of depression ( $40.9 \%$ vs $18.3 \%, P<0.001)$, and anxiety $(28.2 \%$ vs $13.0 \%, P=0.002$ ), whereas age, BMI, WC, FBG, HbA1c, lipids levels, duration of diabetes, proportions of female, and use of glucose lowering drugs were not significantly different between the 2 groups.

Subgroup analysis was performed to observe proportions and risks of symptoms of gastroparesis in different groups. Except for states of anxiety, depression, and fasting C-peptide levels, proportions and odds ratios (ORs) of gastroparesis symptoms did not differ between the groups (Table 4). Patients with anxiety and depression status had a 1.63-fold and 2.08-fold higher ORs, as compared with those without these 2 disorders. Patients with fasting $\mathrm{C}$-peptide levels $\geq 1.84 \mathrm{ng} / \mathrm{mL}$ had significantly decreased OR of gastroparesis symptoms $(\mathrm{OR}, 0.53$; $95 \%$ confidence interval $[\mathrm{CI}], 0.31-0.93$; $P=0.025)$.

\section{Relationships Between Gastrointestinal Symptoms of Gastroparesis and C-peptide Levels}

We also used multivariate analysis to analyze the association between fasting c-peptide levels and GI symptoms. After adjustments for age, sex, BMI, HbAlc, current smoking and drinking status, anxiety, and depression, higher fasting C-peptide levels were still significantly associated with decreased OR of gastroparesis symptoms (OR, $0.67 ; 95 \% \mathrm{CI}, 0.48-0.94 ; P=0.021)$. Additionally, in patients with at least one GI symptom, linear regression revealed that GCSI scores were significantly associated with fasting C-peptide levels (standardized regression coefficient, $-0.29 ; P<0.001$ ) and depression state (standardized regression coefficient, $0.18 ; P=$ $0.002)$. 
Table 3. Clinical and Biochemical Variables in Groups with and Without Gastrointestinal Symptoms of Gastroparesis

\begin{tabular}{|c|c|c|c|}
\hline Variables & $\begin{array}{c}\text { GCSI }<1.9 \\
(n=262)\end{array}$ & $\begin{array}{c}\mathrm{GCSI} \geq 1.9 \\
(\mathrm{n}=71)\end{array}$ & $P$-value \\
\hline Age (yr) & $61.4 \pm 12.2$ & $63.6 \pm 13.2$ & 0.190 \\
\hline Male (n [\%]) & $166(63.4)$ & $40(56.3)$ & 0.280 \\
\hline $\operatorname{BMI}\left(\mathrm{kg} / \mathrm{m}^{2}\right)$ & $24.3 \pm 3.1$ & $24.2 \pm 5.3$ & 0.920 \\
\hline $\mathrm{WC}(\mathrm{cm})$ & $88 \pm 10$ & $87 \pm 11$ & 0.460 \\
\hline $\mathrm{SBP}(\mathrm{mmHg})$ & $133 \pm \pm 14$ & $135 \pm 19$ & 0.290 \\
\hline $\mathrm{DBP}(\mathrm{mmHg})$ & $79 \pm 10$ & $80 \pm 11$ & 0.350 \\
\hline $\mathrm{FPG}(\mathrm{mmol} / \mathrm{L})$ & $8.88 \pm 3.39$ & $9.08 \pm 3.79$ & 0.680 \\
\hline $\operatorname{HbA1c}(\%)$ & $8.4 \pm 2.2$ & $8.3 \pm 2.1$ & 0.990 \\
\hline C-peptide (ng/mL) & $1.94(1.24-2.85)$ & $1.49(0.93-2.31)$ & 0.005 \\
\hline Duration of diabetes (yr) & $10(6-13)$ & $10(7-15)$ & 0.066 \\
\hline $\mathrm{TG}(\mathrm{mmol} / \mathrm{L})$ & $1.59(1.11-2.14)$ & $1.54(1.08-2.30)$ & 0.910 \\
\hline $\mathrm{TC}(\mathrm{mmol} / \mathrm{L})$ & $4.76 \pm 1.25$ & $4.50 \pm 1.08$ & 0.130 \\
\hline HDL-c (mmol/L) & $1.29 \pm 0.39$ & $1.29 \pm 0.51$ & 0.960 \\
\hline LDL-c (mmol/L) & $2.66 \pm 0.87$ & $2.53 \pm 0.66$ & 0.210 \\
\hline Creatinine $(\mathrm{mmol} / \mathrm{L})$ & $72(59-83)$ & $75(55-87)$ & 0.580 \\
\hline Current smoker (n [\%]) & $103(39.3)$ & $21(29.6)$ & 0.130 \\
\hline Current drinker (n [\%]) & $98(37.4)$ & $22(31.0)$ & 0.320 \\
\hline Use of metformin ( $\mathrm{n}[\%]$ ) & $129(49.2)$ & $36(50.7)$ & 0.830 \\
\hline Use of $\alpha$-glycosidase inhibitors (n [\%]) & $67(25.7)$ & $16(22.5)$ & 0.590 \\
\hline Use of DPP4 inhibitors (n [\%]) & $3(1.2)$ & $2(2.8)$ & 0.300 \\
\hline Use of GLP-1 (n [\%]) & $1(0.4)$ & $1(1.4)$ & 0.320 \\
\hline Use of insulin (n [\%]) & $119(45.4)$ & $41(57.8)$ & 0.065 \\
\hline Anxiety (n [\%]) & $34(13.0)$ & $20(28.2)$ & 0.002 \\
\hline Depression (n [\%]) & $48(18.3)$ & $29(40.9)$ & $<0.001$ \\
\hline
\end{tabular}

GCSI, gastroparesis cardinal symptom index; BMI, body mass index; WC, waist circumference; SBP, systolic blood pressure; DBP, diastolic blood pressure; FPG, fasting plasma glucose; HbA1c, glycated hemoglobin A1c; TG, triglycerides; TC, total cholesterol; HDL-c, high density lipoprotein cholesterol; LDL-c, low density lipoprotein cholesterol; DPP4, dipeptidyl peptidase-4; GLP-1, glucagon-like peptide 1.

Data are means $\pm \mathrm{SD}$ or medians (interquartile ranges) or numbers (percentage) of patients.

\section{Discussion}

In the present study, we found that fasting C-peptide levels were significantly decreased in type 2 diabetic patients with GI symptoms of gastroparesis. Higher fasting C-peptide levels were independently associated with decreased risks of gastroparesis symptoms. Moreover, in patients with GI symptoms, GCSI scores were inversely correlated to $\mathrm{C}$-peptide levels.

Accumulating epidemiological studies have revealed that diabetes mellitus is associated with an increased prevalence of GI symptoms. ${ }^{5-7}$ In line with previous studies, ${ }^{5,7}$ our study showed that nearly two-thirds of patients with long duration of diabetes had at least one GI symptom. Among the GI symptoms, "stomach or belly visibly larger after meals" is the most common, while "vomiting" is the least common, which corresponded well to the previous study. ${ }^{7}$
Mechanisms underlying higher prevalence of GI symptoms in diabetic patients are not fully understood. Psychiatric disorders are regarded as contributors to the higher prevalence of GI symptoms in diabetic patients. Previous studies observed that anxiety and depression was associated with higher prevalence of GI symptoms in diabetic patients. ${ }^{17-19}$ A cross-sectional survey conducted in 2091 patients found that the prevalence of severe levels of depression and anxiety was nearly 4-5 fold higher in patients with GI symptoms compared to patients without GI symptoms. ${ }^{23}$ Consistent with previous studies, in the present study, the prevalence of depression and anxiety was significantly higher in patients with GI symptoms of gastroparesis. Additionally, depression was independently associated with GI symptoms even after adjustment for confounding factors, which implies that depression may contribute to GI symptoms in diabetic patients.

Disordered motor function resulted from autonomic neuropa- 
Table 4. Prevalence of Gastrointestinal Symptoms of Gastroparesis in Different Groups and Associations with Clinical Variables

\begin{tabular}{|c|c|c|c|c|}
\hline Variables & \multicolumn{2}{|c|}{ Proportions (\%) } & Odds ratios $(95 \% \mathrm{CI})$ & $P$-value \\
\hline & & \multicolumn{3}{|c|}{ Age } \\
\hline$<60 \mathrm{yr}$ & $26 / 125$ & 20.8 & Reference & \multirow{2}{*}{0.860} \\
\hline$\geq 60 \mathrm{yr}$ & $45 / 208$ & 21.6 & $1.05(0.61-1.81)$ & \\
\hline \multicolumn{5}{|l|}{ Sex } \\
\hline Male & $40 / 206$ & 19.4 & Reference & \multirow{2}{*}{0.280} \\
\hline Female & $31 / 127$ & 24.4 & $1.34(0.79-2.28)$ & \\
\hline \multicolumn{5}{|l|}{ Current smoker } \\
\hline Yes & $21 / 124$ & 16.9 & $0.65(0.37-1.14)$ & \multirow{2}{*}{0.130} \\
\hline No & $50 / 209$ & 23.9 & Reference & \\
\hline \multicolumn{5}{|l|}{ Current drinker } \\
\hline Yes & $22 / 120$ & 18.3 & $0.75(0.43-1.32)$ & \multirow{2}{*}{0.320} \\
\hline No & $49 / 213$ & 23.0 & Reference & \\
\hline \multicolumn{5}{|l|}{ Use of metformin } \\
\hline Yes & $36 / 165$ & 21.8 & $1.06(0.63-1.79)$ & \multirow{2}{*}{0.830} \\
\hline No & $35 / 168$ & 20.8 & Reference & \\
\hline \multicolumn{5}{|l|}{ Anxiety } \\
\hline Yes & $20 / 54$ & 37.0 & $2.63(1.40-4.94)$ & \multirow{2}{*}{0.003} \\
\hline No & $51 / 279$ & 18.3 & Reference & \\
\hline \multicolumn{5}{|l|}{ Depression } \\
\hline Yes & $29 / 77$ & 37.7 & $3.08(1.75-5.43)$ & \multirow{2}{*}{$<0.001$} \\
\hline No & $42 / 256$ & 16.1 & Reference & \\
\hline \multicolumn{5}{|c|}{ Overweight or obese } \\
\hline Yes & $34 / 166$ & 20.5 & $0.89(0.53-1.52)$ & \multirow{2}{*}{0.680} \\
\hline No & $36 / 161$ & 22.4 & Reference & \\
\hline \multicolumn{5}{|l|}{ Hypertension } \\
\hline Yes & $34 / 127$ & 26.8 & $1.67(0.98-2.84)$ & \multirow{2}{*}{0.061} \\
\hline No & $36 / 200$ & 18.0 & Reference & \\
\hline \multicolumn{5}{|l|}{ High TG } \\
\hline Yes & $22 / 123$ & 17.9 & $0.73(0.41-1.31)$ & \multirow{2}{*}{0.290} \\
\hline No & $39 / 170$ & 22.9 & Reference & \\
\hline \multicolumn{5}{|l|}{ Low HDL-c } \\
\hline Yes & $24 / 106$ & 22.6 & $1.18(0.66-2.11)$ & \multirow{2}{*}{0.580} \\
\hline No & $37 / 186$ & 19.9 & Reference & \\
\hline \multicolumn{5}{|l|}{ HbAlc } \\
\hline$<7.8 \%$ & $34 / 147$ & 23.1 & Reference & \multirow{2}{*}{0.930} \\
\hline$\geq 7.8 \%$ & $35 / 154$ & 22.7 & $0.98(0.57-1.67)$ & \\
\hline Duration of diabet & & & & \\
\hline$<10 \mathrm{yr}$ & $27 / 153$ & 17.7 & Reference & \\
\hline$\geq 10 \mathrm{yr}$ & $40 / 168$ & 23.8 & $1.46(0.84-2.52)$ & 0.170 \\
\hline Fasting C-peptide & & & & \\
\hline$<1.84 \mathrm{ng} / \mathrm{mL}$ & $42 / 149$ & 28.2 & Reference & 0025 \\
\hline$\geq 1.84 \mathrm{ng} / \mathrm{mL}$ & $26 / 150$ & 17.3 & $0.53(0.31-0.93)$ & 0.023 \\
\hline
\end{tabular}

TG, triglycerides; HDL-c, high density lipoprotein cholesterol; HbA1c, glycated hemoglobin A1c.

Cutoff points of $7.8 \%$ and $1.84 \mathrm{ng} / \mathrm{mL}$ were medians of $\mathrm{HbAlc}$ and fasting C-peptide, respectively. High TG was defined as fasting TG $\geq 1.7 \mathrm{mmol} / \mathrm{L}$; Low HDL-c was defined as HDL-c $<1.0 \mathrm{mmol} / \mathrm{L}$ in men and $<1.3 \mathrm{mmol} / \mathrm{L}$ in women.

thy is recognized to be one of the causes of GI symptoms. Previous studies suggested that autonomic neuropathy might relate to beta cell function. ${ }^{24-26} \mathrm{~A}$ cross-sectional study demonstrated that preserved c-peptide secretion is associated with a well-balanced cardiac autonomic activity in type 2 diabetic patients. ${ }^{25}$ Johansson et $\mathrm{al}^{26}$ observed that infusion of C-peptide and insulin for 3 months 
may ameliorate autonomic and sensory nerve dysfunction in type 1 diabetes patients. In the present study, we found that decreased Cpeptide levels were associated with GI symptoms independent of other confounding factors including glycemic control and psychiatric disorders. Therefore, we speculate that the association between GI symptoms and C-peptide may be clinical manifestations of the association between autonomic neuropathy and beta cell function. Molecular mechanisms underlying the association between fasting C-peptide and GI symptoms are not clear. However, Zhang and her colleagues ${ }^{27}$ found that enhanced interaction of nuclear factor$\kappa \mathrm{B}(\mathrm{NF}-\kappa \mathrm{B})$ with demethylated purinergic $\mathrm{P} 2 \mathrm{X} 3$ receptor gene contributed to diabetic pain hypersensitivity and insulin treatment significantly attenuated pain hypersensitivity, and suppressed the expression of NF- $\kappa \mathrm{B}$ and P2X3Rs. ${ }^{27}$ Whether C-peptide can improve GI symptoms through this pathway needs further studies for elucidation.

Several cross-sectional studies indicated that poor glycemic control was independently associated with GI symptoms. ${ }^{14-16} \mathrm{~A}$ dose-dependent relationship was detected between upper GI symptoms and $\mathrm{HbA} 1 \mathrm{c}$ in a population-based study. ${ }^{15}$ Nevertheless, some prospective studies yielded contrary results. ${ }^{18,20}$ Quan et al $^{20}$ failed to detect convincing association between GI symptoms and glycemic control over 1 year of follow-up. ${ }^{20}$ In another 2-year followup study, the turnover of GI symptoms in diabetic patients was not associated with glycemic control. ${ }^{18}$ In line with the previous studies, no significant association between HbAlc and GI symptoms was observed in the present study.

Certain oral anti-diabetic drugs may play an important role in causing GI symptoms in diabetic patients. A study indicated that metformin therapy was significantly correlated with GI symptoms of gastroparesis. ${ }^{7}$ In contrast, in our study, although around $50 \%$ of patients were receiving metformin therapy, the proportions were not significantly different between the groups with and without GI symptoms. Further analysis also showed metformin therapy did not associate with a higher risk of GI symptoms of gastroparesis. In line with our results, Bytzer and colleagues ${ }^{28}$ reported that GI symptoms may not be caused by oral anti-diabetic drugs, except for diarrhea which is associated with metformin use. In the present study, the median duration of diabetes is around 10 years; therefore, patients have accommodated to metformin therapy, or if there are any severe GI symptoms, patients may have already switched to other antidiabetic therapies. This may explain the reason that we failed to detect the association between metformin use and GI symptoms. Glucagon-like peptide 1 receptor agonists may also contribute to GI symptoms in diabetic patients. However, only 2 patients were using the drug in the present study. No significant association with GI symptoms was detected.

Some limitations of the present study are noteworthy. First, the present study did not include healthy control subjects and did not compare the prevalence of GI symptoms of gastroparesis in control and diabetic patients; nevertheless, a number of previous studies have shown that diabetic patients have significantly higher prevalence of GI symptoms in comparison to control. Secondly, except for some hypoglycemic drugs, anticholinergic agents, antidepressants, calcium-channel blockers, sedative, and beta-adrenergic agonists may also contribute to GI symptoms. However, we did not collect the information regarding these drugs.

The present study demonstrated that GI symptoms of gastroparesis affect approximately $20 \%$ of type 2 diabetic patients with long duration. Lower fasting C-peptide levels are significantly associated with higher prevalence of GI symptoms of gastroparesis independent of glycemic control and psychiatric disorders. Moreover, in patients with GI symptoms, the severity of GI symptoms is inversely associated with fasting $\mathrm{C}$-peptide levels.

Financial support: The work is supported by grants from the National Natural Science Foundation of China (Grant No. 81471041 and 81502865), the Natural Science Foundation of Jiangsu Province (Grant No. SBK201340560), and the Natural Science Foundation for Colleges and Universities in Jiangsu Province (Grant No. 13KJB320017).

\section{Conflicts of interest: None.}

Author contributions: Yun Huang participated in the study design, performed the statistical analysis, and drafted the manuscript; Honghong Zhang conceived the study, participated in the study design, and contributed intellectual content of discussion; Minxia Zhang, Wenya Li, and Jinhua Wang recruited patients and collect the data; and Ji Hu conceived, designed the study, and revised the manuscript for important intellectual content. All authors have read and approved revised manuscript.

\section{References}

1. Camilleri M, Bharucha AE, Farrugia G. Epidemiology, mechanisms, and management of diabetic gastroparesis. Clin Gastroenterol Hepatol 2011;9:5-12.

2. Choung RS, Locke GR 3rd, Schleck CD, Zinsmeister AR, Melton LJ 3rd, Talley NJ. Risk of gastroparesis in subjects with type 1 and 2 diabetes in the general population. Am J Gastroenterol 2012;107:82-88. 
3. Feldman M, Schiller LR. Disorders of gastrointestinal motility associated with diabetes mellitus. Ann Intern Med 1983;98:378-384.

4. Maleki D, Locke GR 3rd, Camilleri M, et al. Gastrointestinal tract symptoms among persons with diabetes mellitus in the community. Arch Intern Med 2000;160:2808-2816.

5. Ko GT, Chan WB, Chan JC, Tsang LW, Cockram CS. Gastrointestinal symptoms in Chinese patients with type 2 diabetes mellitus. Diabet Med 1999;16:670-674.

6. Bytzer P, Talley NJ, Leemon M, Young LJ, Jones MP, Horowitz M. Prevalence of gastrointestinal symptoms associated with diabetes mellitus: a population-based survey of 15,000 adults. Arch Intern Med 2001;161:1989-1996

7. Dickman R, Kislov J, Boaz M, et al. Prevalence of symptoms suggestive of gastroparesis in a cohort of patients with diabetes mellitus. J Diabetes Complications 2013;27:376-379.

8. Talley NJ, Young L, Bytzer P, et al. Impact of chronic gastrointestinal symptoms in diabetes mellitus on health-related quality of life. Am J Gastroenterol 2001;96:71-76.

9. Bharucha AE, Camilleri M, Low PA, Zinsmeister AR. Autonomic dysfunction in gastrointestinal motility disorders. Gut 1993;34:397-401.

10. Rayner CK, Samsom M, Jones KL, Horowitz M. Relationships of upper gastrointestinal motor and sensory function with glycemic control. Diabetes Care 2001;24:371-381.

11. Ekberg K, Brismar T, Johansson BL, et al. C-peptide replacement therapy and sensory nerve function in type 1 diabetic neuropathy. Diabetes Care 2007;30:71-76.

12. Ekberg $\mathrm{K}$, Johansson BL. Effect of C-peptide on diabetic neuropathy in patients with type 1 diabetes. Exp Diabetes Res 2008;2008:457912.

13. Bharucha AE, Batey-Schaefer B, Cleary PA, et al. Delayed gastric emptying is associated with early and long-term hyperglycemia in type 1 diabetes mellitus. Gastroenterology 2015;149:330-339.

14. Rayner CK, Samsom M, Jones KL, Horowitz M. Relationships of upper gastrointestinal motor and sensory function with glycemic control. Diabetes Care 2001;24:371-381.

15. Bytzer P, Talley NJ, Hammer J, Young LJ, Jones MP, Horowitz M. GI symptoms in diabetes mellitus are associated with both poor glycemic control and diabetic complications. Am J Gastroenterol 2002;97:604611.

16. Kofod-Andersen K, Tarnow L. Prevalence of gastroparesis-related symptoms in an unselected cohort of patients with Type 1 diabetes. J Diabetes Complications 2012;26:89-93.
17. de Kort S, Kruimel JW, Sels JP, Arts IC, Schaper NC, Masclee AA. Gastro intestinal symptoms in diabetes mellitus, and their relation to anxiety and depression. Diabetes Res Clin Pract 2012;96:248-255.

18. Quan C, Talley NJ, Jones MP, Spies J, Horowitz M. Gain and loss of gastrointestinal symptoms in diabetes mellitus: associations with psychiatric disease, glycemic control, and autonomic neuropathy over 2 years of follow-up. Am J Gastroenterol 2008;103:2023-2030.

19. Talley SJ, Bytzer P, Hammer J, Young L, Jones M, Horowitz M. Psychological distress is linked to gastrointestinal symptoms in diabetes mellitus. Am J Gastroenterol 2001;96:1033-1038.

20. Quan C, Talley NJ, Jones MP, Howell S, Horowitz M. Gastrointestinal symptoms and glycemic control in diabetic mellitus: a longitudinal population study. Eur J Gastroenterol Hepatol 2008;20:888-897.

21. Revicki DA, Rentz AM, Dubois D, et al. Development and validation of a patient-assessed gastroparesis symptom severity measure: the Gastroparesis Cardinal Symptom Index. Aliment Pharmacol Ther 2003;18:141150.

22. Spinhoven P, Ormel J, Sloekers PP, Kempen GI, Speckens AE, Van Hemert AM. A validation study of the Hospital Anxiety and Depression Scale (HADS) in different groups of Dutch subjects. Psychol Med 1997;27:363-370.

23. Mussell M, Kroenke K, Spitzer RL, Williams JB, Herzog W, Löwe B. Gastrointestinal symptoms in primary care: prevalence and association with depression and anxiety. J Psychosom Res 2008;64:605-612.

24. Zhao L, Ma J, Wang S, Xie Y. Relationship between $\beta$-cell function, metabolic control, and microvascular complications in type 2 diabetes mellitus. Diabetes Technol Ther 2015;17:29-34

25. Manzella D, Carbonella M, Ragno E, Passariello N, Grella R, Paolisso G.Relationship between autonomic cardiac activity, beta-cell function, anthropometrics and metabolic indices in type II diabetics. Clin Endocrinol (Oxf) 2002;57:259-264.

26. Johansson BL, Borg K, Fernqvist-Forbes E, Odergren T, Remahl S, Wahren J. C-peptide improves autonomic nerve function in IDDM patients. Diabetologia 1996;39:687-695.

27. Zhang HH, Hu J, Zhou YL, et al. Promoted interaction of nuclear factor- $\kappa \mathrm{B}$ with demethylated purinergic $\mathrm{P} 2 \mathrm{X} 3$ receptor gene contributes to neuropathic pain in rats with diabetes. Diabetes 2015;64:4272-4284.

28. Bytzer P, Talley NJ, Jones MP, Horowitz M. Oral hypoglycaemic drugs and gastrointestinal symptoms in diabetes mellitus. Aliment Pharmacol Ther 2001;15:137-142. 